\title{
Tamanho de grão comercial em cultivares de feijoeiro
}

\author{
Commercial grain size in common bean cultivars
}

\section{Sérgio Augusto Morais Carbonell ${ }^{*}$ Alisson Fernando Chiorato ${ }^{\mathrm{I}}$ João Guilherme Ribeiro Gonçalves ${ }^{\mathrm{II}}$ Eliana Francischinelli Perina ${ }^{\mathrm{II}}$ Cássia Regina Limonta Carvalho ${ }^{\mathrm{II}}$}

RESUMO

\begin{abstract}
Os objetivos do trabalho foram avaliar e indicar parâmetros de seleção para classificação de grãos de feijão que atendam as exigências do mercado consumidor. Foram instalados experimentos contendo 19 genótipos de feijoeiro em nove ambientes, no Estado de São Paulo. A produção de grãos foi estratificada em peneiras de classificação 10 (10/64" pol.) a 15 (15/64" pol.) e avaliada a produção relativa de grãos em peneiras 13 e 14, rendimento de peneira, massa de 1.000 grãos, tamanho de grãos e para os índices $J=$ perfil $e$ $H=$ forma do grão. A produção relativa de grãos, rendimento de peneira, forma e perfil foram as características que apresentaram diferenças estatísticas significativas, indicando presença de variabilidade genética. Por meio da comparação dos resultados com testemunhas de feijoeiro já recomendadas para o setor produtivo, conclui-se que uma cultivar de feijoeiro deve apresentar alta massa de 1.000 grãos (251 a 300g), produção relativa de grãos em peneiras 13 e 14 com valores acima de sete, rendimento de peneira acima de 70,0\% e também sementes elípticas e perfil semiachatado.
\end{abstract}

Palavras-chave: Phaseolus vulgaris, rendimento, peneira, produtividade, estabilidade.

\section{ABSTRACT}

The aim of this research was to evaluate and to direct the genetic parameters to classify the grain size of common bean, according to the market demand. Experiments with 19 common bean genotypes were assembled in nine sites in the São Paulo State. The grain yield was stratified following sieve classification 10 (10/64" inch) to 15 (15/64" inch). The following parameters were evaluated: relative yield with 13 and 14 sieves, sieve yield, thousand grain weight, grain size, J and $H$ indexes $(J=$ grain profile; $H=$ grain shape). The relative grain yield, sieve yield, shapes and grain profiles presented significant statistical differences, indicating the presence of genetic variability among the genotypes. Compared to the market recommended and productive checks, the results showed that a common bean cultivar should present high thousand grain weight (251 to 300g); relative grain yield with 13 and 14 sieves should present values above seven; the sieve yield should be above $70.0 \%$ and it should exhibit elliptic seeds and semiflat grain.

Key words: Phaseolus vulgaris, yield, sieve, grain yield, stability.

\section{INTRODUÇÃO}

O feijão, em conjunto com o arroz, é um prato quase obrigatório na dieta dos brasileiros, pois é considerado a principal fonte de proteínas de consumo diário e destaca-se por ser um produto de alta expressão sócio-econômica (CARNEIRO \& PARRÉ, 2005). Com relação à aceitação e preferência pelos consumidores, deve-se levar em consideração aspectos relacionados à cor, ao tamanho e ao brilho dos grãos. De acordo com COLLICCHIO et al. (1997), ocorreram importantes mudanças no sistema de produção do feijoeiro, uma vez que deixou de ser um cultivo exclusivamente de subsistência para sistemas altamente tecnificados. Diante disso, os programas de melhoramento passaram

'Centro de Grãos e Fibras, Instituto Agronômico, CP 28, 13012-970, Campinas, SP, Brasil. E-mail: carbonel@iac.sp.gov.br. Autor para correspondência.

"Curso PG/IAC/APTA, Campinas, SP, Brasil.

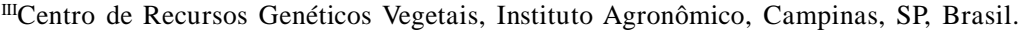


a buscar nas cultivares não somente alta produtividade e resistência a pragas e doenças como características agronômicas, mas também características de qualidade tecnológica, como porte ereto, coloração clara de grãos e grãos graúdos com peneiras acima de 12, constituindo-se em características que promovem uma melhor aceitação de mercado (MELO et al., 2007).

Dessa forma, esses programas passaram a desenvolver cultivares que não atendessem somente os produtores, mas também as empresas empacotadoras e o consumidor final (CHIORATO et al., 2009). Até meados de 1998, o tamanho de grão considerado como padrão era o da cultivar 'Carioca' ou 'Carioquinha', que apresentava tamanho médio de grãos entre as peneiras 11 e 12. Após 1998, esse padrão foi modificado com o surgimento da cultivar 'Pérola', passando para o tamanho médio entre as peneiras 12 e 13 e tornandose preferido pelas empresas empacotadoras e pelo consumidor final, que definem as exigências de mercado. As empresas empacotadoras passaram a aliar as "marcas do produto" ao tipo de grão, juntamente com a coloração clara de grão, e o consumidor associou grãos maiores a um melhor rendimento de panela, costituindo-se em uma maior expansão dos grãos após o cozimento. É importante salientar que não é somente o tamanho do grão que determina o sucesso de uma cultivar, mas também as demais características, como a cor, o tempo de cozimento, a porcentagem de grãos inteiros após o cozimento, o brilho dos grãos, a produtividade e a resistência da cultivar a fatores bióticos e abióticos.

Diante do exposto, o presente trabalho teve por objetivos avaliar e indicar parâmetros relacionados à qualidade de grãos em 19 genótipos de feijoeiro, provenientes dos principais programas de melhoramento do Brasil visando a obter resultados que melhor atendam o consumidor final e que possam ser utilizados pelos programas de melhoramento de feijoeiro.

\section{MATERIAL E MÉTODOS}

Os dados foram coletados em nove experimentos de Valor de Cultivo e Uso (VCU) cultivados em diferentes municípios, no Estado de São Paulo, sendo compostos por 19 genótipos, semeados nas épocas "de inverno" de 2006 (Colina, Ribeirão Preto e Fernandópolis), "das águas' de 2006 (Avaré, Mococa, Capão Bonito) e "da seca" de 2007 (Tatuí, Avaré e Monte Alegre do Sul). Dos 19 genótipos estudados, é importante citar que a IAC Alvorada e Pérola são cultivares já utilizada pelos agricultores em razão de suas características de interesse. Dessa forma, essas cultivares foram utilizadas como testemunhas de comparação com os demais genótipos. Os experimentos foram instalados conforme as normas do MAPA/RNC - Ministério da Agricultura, Pecuária e Abastecimento/ Registro Nacional de Cultivares para ensaios de VCU, constituindo-se em experimentos em blocos casualizados, com três repetições e parcelas de quatro linhas de quatro metros espaçadas em $0,50 \mathrm{~m}$ entre linhas (área útil da parcela sendo as duas linhas centrais).

Após a colheita e trilhagem dos experimentos, foi mensurada a produtividade de cada parcela para obter o rendimento médio de cada genótipo e posteriormente foi realizado o agrupamento das parcelas, sendo em seguida a produção de grãos devidamente limpa para retirada de impurezas. Grãos que passaram pela peneira 10 (10/64" pol.) foram descartados devido ao baixo valor comercial. Em seguida, foi realizada a medição do peso de cada peneira, ou seja, 10 (10/64" pol.) a 15 (15/64" pol.), em que também foram coletadas ao acaso cinco repetições de cinco grãos dentro de cada peneira para as avaliações quanto à forma e ao perfil dos grãos.

Com relação à produção parcial dos genótipos, nos diferentes ambientes, os grãos foram classificados em peneiras com furos oblongos de número 10 (10/64" pol.), 11 (11/64" pol.), 12 (12/64" pol.), 13 (13/64" pol.), 14 (14/64" pol.) e 15 (15/64" pol.), para a determinação da produção de grãos em cada peneira. Com o objetivo de obter uma classificação de cada genótipo para posterior ordenamento, o peso dos grãos retidos em cada peneira foi submetido a uma escala de pesos/notas, em que, para a peneira 10 , foi estipulado peso 1; para a peneira 11, peso 4; para a peneira 12, peso 6; para a peneira 13 , peso 10 ; para a peneira 14, peso 10; e para a peneira 15, peso 6. Essas medidas de peso/nota foram estabelecidas em função da exigência da indústria empacotadora e do mercado consumidor. Para isso, foram visitadas as principais empacotadoras do Estado de São Paulo para verificar qual o melhor tipo de grão em função do tamanho (rendimento de peneira e aspecto visual), da coloração (qualidade visual de prateleira e resistência ao escurecimento) e do tempo de cocção (qualidades culinárias). Por meio dos resultados coletados, foi elaborada a seguinte fórmula:

$$
\text { PRGP }=\frac{(P 13 x \text { Peso } 10)+(P 14 x \text { Peso } 10)+(\text { P15xPeso } 6)}{P 10+P 11+P 12+P 13+P 14+P 15}
$$

em que PRGP: Produção Relativa de Grãos em Peneiras; P10: peso (g) retido na peneira de furo oblongo de número 10; P11: peso $(\mathrm{g})$ retido na peneira de furo 
oblongo de número 11; P12: peso $(\mathrm{g})$ retido na peneira de furo oblongo de número 12; $\mathrm{P} 13$ : peso $(\mathrm{g})$ retido na peneira de furo oblongo de número 13; P14: peso $(\mathrm{g})$ retido na peneira de furo oblongo de número 14; e P15: peso $(\mathrm{g})$ retido na peneira de furo oblongo de número 15.

Outra medida de relevante importância foi o rendimento de peneira (RP\%), conforme a fórmula descrita abaixo.

$$
\begin{aligned}
R P \%= & \frac{P 12+P 13+P 14+P 15}{P 10+P 11+P 12+P 13+P 14+} \times 100, \\
& P 15+\text { Descarte }
\end{aligned}
$$

em que RP\%: rendimento de peneira; $\mathrm{P} 10$ : peso (g) retido na peneira de furo oblongo de número 10; P11: peso (g) retido na peneira de furo oblongo de número 11; P12: peso (g) retido na peneira de furo oblongo de número 12; P13: peso $(\mathrm{g})$ retido na peneira de furo oblongo de número 13; P14: peso $(\mathrm{g})$ retido na peneira de furo oblongo de número 14; e P15: peso $(\mathrm{g})$ retido na peneira de furo oblongo de número 15.

Paralelamente a essa operação foram separadas de forma aleatória cinco repetições de cinco grãos de cada peneira para as medições quanto ao tamanho, à espessura e ao comprimento dos grãos por meio de um paquímetro digital para a quantificação dos índices J (razão entre o comprimento e a largura em $\mathrm{mm}$ ), que corresponde à forma de grãos, e o índice $\mathrm{H}$ (razão entre espessura e largura em mm), que corresponde ao perfil, segundo PUERTA ROMERO (1961).

Os caracteres, como produtividade, índice J e índice $\mathrm{H}$, foram avaliados quanto à análise de estabilidade, sendo utilizada a metodologia proposta por LIN \& BINNS (1988) e modificada por CARNEIRO (1998). Para a realização da análise de estabilidade dos índices $\mathrm{J}$ e $\mathrm{H}$, foram utilizados os dados referentes às duas peneiras de furos oblongos que apresentaram as maiores porcentagens de grãos, pois teoricamente representará o tipo de grão característico do genótipo. Isso vale para cada genótipo, incluindo os nove ambientes avaliados.

Para que a recomendação atenda ao conceito de grupos de ambientes favoráveis e desfavoráveis, CARNEIRO (1998) fez a decomposição do estimador Pi proposto por LIN \& BINNS (1988) em estimadores $P_{\text {if }}$ (referente a ambientes favoráveis) e $\mathrm{P}_{\text {id }}$ (referente a ambientes desfavoráveis), que refletem, de certa forma, em ambientes onde há emprego de alta e baixa tecnologia, respectivamente. A classificação de ambiente em favorável ou desfavorável é feita com base nos índices ambientais, definidos como a diferença entre a média dos genótipos avaliados em cada local e a média geral. Os experimentos (locais) que apresentam maior média em relação à média geral constituem os ambientes favoráveis (Pif), e aqueles com média menor que a média geral são classificados como ambientes desfavoráveis (Pid).

\section{RESULTADOS E DISCUSSÃO}

De posse dos resultados, foram observadas diferenças entre os genótipos em relação à Produção Relativa de Grãos em Peneiras (PRGP), na qual foram atribuídos diferentes pesos/notas de acordo com as exigências dos consumidores (Tabela 1). No presente trabalho, as peneiras de número 13 e 14 foram consideradas as mais importantes devido à atual demanda do mercado consumidor indicada pela indústria empacotadora. Pelo teste de Tukey, observase uma diferença estatística para a variável em questão, indicando que os genótipos comportaram-se de maneira distinta quando cultivados nas diferentes épocas de cultivo.

Para a cultivar 'IAC-Alvorada', observouse superioridade na média de cada época, bem como na média das três épocas de semeadura, em relação ao tipo de grão (Tabela 1). Essa característica atende as exigências do consumidor final, pois essa cultivar apresenta grãos maiores quando comparados às demais cultivares disponíveis no mercado consumidor (CARBONELL et al., 2008). Nesses ambientes, a cultivar 'IAC-Alvorada' obteve maior porcentagem de grãos em peneiras de número 13 e 14, estabelecida no presente trabalho como um parâmetro referente a uma aceitação de $100 \%$ pelo consumidor, justificando, dessa forma, a atribuição dos pesos/notas iguais a 10 para essas peneiras. A cultivar 'IAC-Diplomata' obteve também índice satisfatório de PRPG por ser uma linhagem irmã da cultivar 'IAC-Alvorada', sendo ambas oriundas de cruzamentos realizados no Instituto Agronômico - IAC.

A cultivar 'Pérola' obteve valor médio das três safras para PRGP inferior aos genótipos 'IACAlvorada', 'IAC Diplomata', 'LP 0138', 'LP 02130', 'CV 48', 'Gen 96A98-15', 'Gen 96A45', 'BRS-Grafite' e 'IAC Una' (Tabela 1). Esse resultadoé um indicativo que os programas de melhoramento no Brasil estão preocupados com o tamanho do grão, realizando ensaios de VCU com linhagens que apresentem grãos semelhantes ou superiores estatisticamente ao da cultivar 'Pérola'. Desse modo, valores de PRPG acima de 7,0 provavelmente terão boa aceitação de mercado, mas, além dessa característica, outros atributos de qualidade, como coloração, massa de 1.000 grãos, forma e perfil deverão ser atendidos também pela cultivar.

Vale ressaltar que os maiores pesos/notas foram atribuídos para as peneiras 13 e 14, uma vez que 
Tabela 1 - Resultado da Produção Relativa de Grãos em Peneiras (PRGP) de furos oblongos e produtividade de grãos (kg ha ${ }^{-1}$ ) para as 19 linhagens e cultivares de feijão avaliadas em nove ambientes.

\begin{tabular}{|c|c|c|c|c|c|}
\hline \multirow[b]{2}{*}{ Genótipos } & "Das águas" & "Da seca" & "De inverno" & Média & \multirow[b]{2}{*}{$\begin{array}{c}\text { Produtividade gera } \\
\qquad\left(\mathrm{kg} \mathrm{ha}^{-1}\right)\end{array}$} \\
\hline & Média & Média & Média & Geral & \\
\hline IAC-Alvorada & 7,89 & 8,28 & 7,62 & $7,93 \mathrm{a}$ & $2536 a b c$ \\
\hline IAC-Diplomata & 7,79 & 7,43 & 6,84 & $7,35 \mathrm{ab}$ & $2485 \mathrm{abc}$ \\
\hline LP 01-38 & 7,52 & 7,95 & 6,42 & $7,29 \mathrm{ab}$ & $2797 \mathrm{a}$ \\
\hline LP 02-130 & 7,39 & 7,08 & 5,87 & $6,78 \mathrm{bc}$ & $2673 \mathrm{ab}$ \\
\hline Gen 96A98-15 & 7,11 & 6,85 & 6,07 & $6,68 \mathrm{bcd}$ & $2291 \mathrm{bc}$ \\
\hline CV -48 & 6,60 & 7,23 & 6,18 & $6,67 \mathrm{bcd}$ & $2504 \mathrm{abc}$ \\
\hline IAC-Una & 7,10 & 7,21 & 5,31 & 6,54 bcde & $2683 \mathrm{ab}$ \\
\hline BRS-Grafite & 5,68 & 7,08 & 6,70 & 6,49 bcdef & $2478 \mathrm{abc}$ \\
\hline Gen 96A45 & 6,98 & 6,89 & 5,32 & 6,40 bcdefg & $2473 \mathrm{abc}$ \\
\hline Pérola & 6,70 & 6,91 & 5,60 & 6,40 bcdefg & $2773 \mathrm{a}$ \\
\hline Gen 93A3 & 6,30 & 6,88 & 5,97 & 6,39 bcdefg & $2193 c$ \\
\hline Z-28 & 7,43 & 6,27 & 4,75 & 6,15 cdefgh & $2561 \mathrm{abc}$ \\
\hline LP 98-122 & 5,36 & 6,10 & 5,48 & 5,65 defghi & $2622 \mathrm{abc}$ \\
\hline BRS-Pontal & 5,86 & 5,56 & 5,19 & 5,54 efghi & $2818 \mathrm{a}$ \\
\hline BRS-Supremo & 5,63 & 5,77 & 4,77 & 5,39 fghi & $2448 \mathrm{abc}$ \\
\hline BRS-Requinte & 5,05 & 5,74 & 5,26 & 5,35 ghi & $2556 \mathrm{abc}$ \\
\hline IPR Siriri & 5,13 & 5,81 & 4,15 & $5,03 \mathrm{hi}$ & $2754 \mathrm{ab}$ \\
\hline IAC-Tybatã & 4,24 & 5,91 & 4,36 & $4,84 \mathrm{i}$ & $2412 \mathrm{abc}$ \\
\hline FT-Nobre & 4,43 & 5,25 & 4,42 & $4,70 \mathrm{i}$ & $2589 \mathrm{abc}$ \\
\hline Média & 6,33 & 6,64 & 5,59 & 6,19 & 2560 \\
\hline CV\% & 8,04 & 9,90 & 11,03 & 10,76 & 10,87 \\
\hline
\end{tabular}

*Médias não seguidas da mesma letra diferem entre si, com 5\% de probabilidade, pelo teste de Tukey.

a demanda atual de mercado para o tamanho médio dos grãos de feijoeiro está em torno dessas peneiras. Sendo assim, as cultivares 'IAC-Alvorada' (carioca) e 'IAC-Diplomata' (Preto) e as linhagens 'LP 0138' (carioca), 'LP 02130' (Preto) e 'CV-48' (carioca) foram superiores para PRGP, em comparação com os demais genótipos em estudo. No caso das linhagens 'LP 0138' e 'LP 02130', em média, estas apresentaram peneiras de tamanho 12, mas o potencial produtivo dessas linhagens e a estabilidade no tamanho de grãos para peneira 12 fizeram as linhagens apresentarem um bom desempenho para PRGP, por meio da fórmula estipulada para essa característica (Tabelas 1 e 2).

$\mathrm{O}$ rendimento de peneira (RP\%) dos 19 genótipos semeados em nove ambientes no Estado de São Paulo são apresentados na tabela 2. A cultivar 'IAC-Alvorada' mostrou-se superior no ordenamento das cultivares no conjunto das três épocas de semeadura. Embora tenha obtido igualdade na significância do teste de média, isso demonstra uma forte tendência de superioridade dessa cultivar, mesmo quando comparada ao padrão 'Pérola'.
Além da cultivar 'IAC-Alvorada' (rendimento de peneira de $74,72 \%$ ), a cultivar 'IACDiplomata' (rendimento de peneira de $72,27 \%$ ) e as linhagens 'LP 01-38' (rendimento de peneira de 72,23\%) e 'LP 02130' (rendimento de peneira 68,69\%) também apresentaram as maiores médias na avaliação conjunta das épocas de semeadura. Esses genótipos foram os que mais se destacaram, apresentando os maiores rendimentos de peneira (RP\%), valores superiores às cultivares testemunhas para ambos os tipos comerciais ('Pérola': 59,76 e 'IAC-Una': 62,85). Essa característica é de grande importância para o tipo de grão carioca, uma vez que o mercado consumidor atual tem preferência para grãos graúdos, com alta massa de 1.000 grãos e alto rendimento de peneira. PERINA et al. (2010) citam que genótipos com alta massa de 1000 grãos proporcionam maior rendimento de peneira e também uma maior expansão volumétrica $\left(0,54 \mathrm{~g} \mathrm{ml}^{-1}\right)$, proporcionando um maior rendimento de panela (característica desejável pelo consumidor e pela indústria empacotadora).

Ciência Rural, v.40, n.10, out, 2010. 
Tabela 2 - Rendimento de peneira (RP\%) e produtividade de grãos $\left(\mathrm{kg} \mathrm{ha}^{-1}\right)$ para as 19 linhagens e cultivares de feijão avaliadas em nove ambientes.

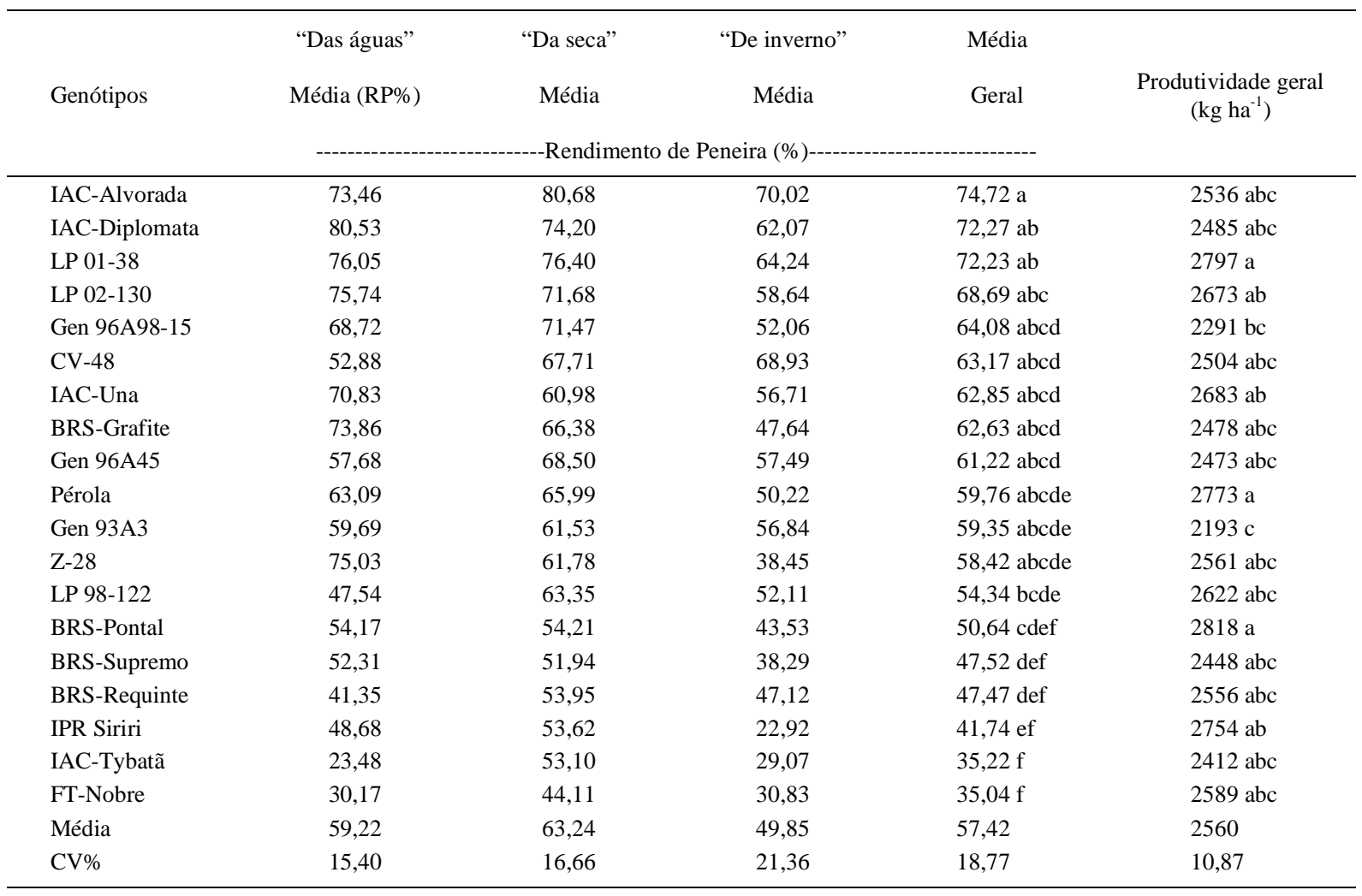

*Médias não seguidas da mesma letra diferem entre si, com nível de 5\% de probabilidade, pelo teste de Tukey.

Para as análises de estabilidade em relação ao índice J (Tabela 3), com base no método de LIN \& BINNS (1988) modificado por CARNEIRO (1998), os genótipos mais estáveis quanto à forma dos grãos foram: 'IAC-Diplomata' (elíptica), 'CV-48' (elíptica) e 'Gen 96A45-3-51-52-1' (elíptica). Os genótipos 'CV-48', 'IPR Siriri' (elíptica) e 'Gen 96A45-3-51-52-1' foram os mais responsivos, bem como os mais tolerantes a ambientes desfavoráveis. No entanto, pode-se concluir que, para o índice J, as linhagens 'Gen 96A45-3-51-521 'e 'CV-48' foram as que melhor se destacaram, sendo estáveis, responsivas e tolerantes a ambientes desfavoráveis. Quanto a essa característica, pode-se observar, pelo teste de Tukey, que houve diferença estatística entre os genótipos, na qual a 'IACDiplomata' (1,62mm) e 'BRS-Requinte' (1,41 mm) apresentaram o maior e o menor valor, respectivamente, em relação à forma do grão, conforme mencionados na tabela 3 .
Em relação ao mercado, o índice $\mathrm{J}$ é importante para determinar o padrão de mercado elíptico como desejável, sendo as formas esféricas e reniformes consideradas fora do padrão comercial. Somente a cultivar 'BRS-Requinte' apresentou a forma dos grãos esférica e teoricamente fora do padrão comercial, no entanto, devido ao seu valor 1,416 estar próximo do valor inferior da classe Elíptica $(1,43)$ e apresentar o maior valor de $\mathrm{P}_{\mathrm{i}}$ (menor estabilidade para formato de grão), pode-se considerá-la também como grão Elíptico. Também em relação ao índice $\mathrm{J}$, avaliando o posicionamento dos genótipos na tabela 3, pode-se considerar que os valores ideais para fins de mercado estão próximos à média da classe elíptica $(1,54)$.

Para o índice $\mathrm{H}$ (Tabela 4), que representa o perfil dos grãos, os genótipos mais estáveis foram 'IACDiplomata' (cheia), 'LP 01-38' (semiachatada) e 'IACAlvorada' (semi-achatada), diferindo estatisticamente dos demais. Os genótipos 'LP 01-38', 'IAC-Diplomata' 
Tabela 3 - Parâmetros de estabilidade $\mathrm{P}_{\mathrm{i}}$ obtidos pelo método de LIN e BINNS modificado por CARNEIRO, a partir da decomposição em ambientes favoráveis $\left(\mathrm{P}_{\mathrm{if}}\right)$ e desfavoráveis $\left(\mathrm{P}_{\mathrm{id}}\right)$, para o índice $\mathrm{J}$ (Forma do grão em mm).

\begin{tabular}{|c|c|c|c|c|c|}
\hline Cultivares e linhagens de feijoeiro & $\operatorname{Média~}(\mathrm{mm})-\hat{\beta}_{0 i}$ & $\begin{array}{l}\text { Forma do grão } \\
\quad \text { (índice J) }\end{array}$ & $\mathrm{P}_{\mathrm{i}}\left(10^{4}\right)$ & $\mathrm{P}_{\mathrm{if}}\left(10^{4}\right)$ & $\mathrm{P}_{\text {id }}\left(10^{4}\right)$ \\
\hline IAC - Diplomata & $1,6233 \mathrm{a}$ & Elíptica & 0,001 & 0,0018 & 0 \\
\hline $\mathrm{CV}-48$ & $1,6056 \mathrm{ab}$ & Elíptica & 0,001 & 0,0013 & 0,0006 \\
\hline Gen 96A45-3-51-52-1 & $1,5944 \mathrm{abc}$ & Elíptica & 0,0019 & 0,0017 & 0,0022 \\
\hline IPR Siriri & $1,5911 \mathrm{abc}$ & Elíptica & 0,0022 & 0,0015 & 0,0032 \\
\hline $\mathrm{Z}-28$ & 1,5756 abcd & Elíptica & 0,0031 & 0,0023 & 0,0042 \\
\hline FT- Nobre & 1,5633 bcde & Elíptica & 0,0038 & 0,0023 & 0,0056 \\
\hline LP-98-122 & 1,5567 bcdef & Elíptica & 0,0045 & 0,0043 & 0,0048 \\
\hline IAC - Alvorada & 1,5422 cdefg & Elíptica & 0,0053 & 0,0052 & 0,0055 \\
\hline IAC- Carioca Tybatã & 1,5311 defgh & Elíptica & 0,0075 & 0,0094 & 0,0052 \\
\hline BRS- Grafite & 1,5189 defgh & Elíptica & 0,0094 & 0,0059 & 0,0138 \\
\hline BRS- Pontal & 1,5167 efgh & Elíptica & 0,0088 & 0,0094 & 0,008 \\
\hline Pérola & $1,4989 \mathrm{fgh}$ & Elíptica & 0,0111 & 0,0089 & 0,0138 \\
\hline Gen 96A3 P1-1-1 & 1,4911 ghi & Elíptica & 0,0118 & 0,0109 & 0,0129 \\
\hline LP 01-38 & 1,4867 ghij & Elíptica & 0,0124 & 0,0111 & 0,014 \\
\hline Gen 96A98- 15-3-52-1 & $1,4811 \mathrm{hij}$ & Elíptica & 0,0136 & 0,0127 & 0,0148 \\
\hline LP 02-130 & 1,4767 hij & Elíptica & 0,015 & 0,018 & 0,0112 \\
\hline IAC-Una & $1,4333 \mathrm{ijk}$ & Elíptica & 0,022 & 0,0228 & 0,021 \\
\hline BRS - Supremo & $1,4311 \mathrm{jk}$ & Elíptica & 0,0232 & 0,0234 & 0,0229 \\
\hline BRS - Requinte & $1,4167 \mathrm{k}$ & Esférica & 0,0264 & 0,0253 & 0,0277 \\
\hline Média & 1,52 & - & - & - & - \\
\hline Coeficiente de variação (\%) & 5,11 & - & - & - & - \\
\hline
\end{tabular}

*Médias não seguidas da mesma letra diferem entre si, com nível de 5\% de probabilidade, pelo teste de Tukey.

e 'Gen 96A3-P1-1-1' (semiachatada) foram os mais responsivos, e os genótipos 'IAC-Diplomata', 'IACAlvorada' e 'LP 02-130' (semiachatada) apresentaramse como tolerantes a ambientes desfavoráveis.

Conforme a tabela 4, observa-se que, para o caráter perfil do grão, os genótipos diferiram estatisticamente pelo teste de Tukey, e as cultivares 'BRS Pontal' e 'IAC-Carioca Tybatã' apresentaram o menor valor, sendo classificadas como achatadas, característica não aceita pelo mercado consumidor, que apresenta preferência por grãos cheios e grandes. No entanto, como foi considerada a necessidade de grãos grandes, o perfil deve ser semiachatado para não ocorrer uma forma esférica. Assim, grãos com perfil semiachatado com valores próximos ao perfil cheio (maior que 0,77) e forma elíptica são padrões valorizados pelo mercado consumidor.

Com relação à produtividade (Tabelas $1 \mathrm{e}$ 2), os genótipos 'Pérola', 'IPR Siriri' e 'LP 01-38' foram os mais produtivos. Esse resultado é importante, pois demonstra que a cultivar 'Pérola' é largamente cultivada nas condições brasileiras por se mostrar estável para produtividade e apresentar boa qualidade de grão. Observa-se também que houve uma considerável diferença estatística pelo teste de Tukey para a variável produtividade, em que os genótipos 'BRS-Pontal' (2.818kg ha'), 'LP 01-38' (2.797kg ha' ${ }^{-1}$ e 'Pérola' $\left(2.773 \mathrm{~kg} \mathrm{ha}^{-1}\right)$ destacaram-se na ordem como os mais produtivos, e o 'Gen 96A3 P1-1-1' (2.193kg ha-1) se destacou como o menos produtivo. Esse resultado é um indicativo que os genótipos estudados apresentam, potencialmente, elevada produtividade (acima de $\left.2.560 \mathrm{~kg} \mathrm{ha}^{-1}\right)$, não sendo essa característica um fator limitante para o lançamento de novas cultivares, permitindo aumentar a busca por genótipos produtivos e com alta qualidade de grãos.

\section{CONCLUSÃO}

Os programas de melhoramento devem selecionar cultivares de feijoeiro que apresentem rendimento de peneira acima de $70 \%$, produção relativa de grãos em peneiras 13 e 14 acima de sete, sementes elípticas (índice J) com valor próximo a 1,54 e perfil de grãos semiachatados, com valor próximo a 0,77 . 
Tabela 4 - Parâmetros de estabilidade $\mathrm{P}_{\mathrm{i}}$ obtidos pelo método de LIN e BINNS modificado por CARNEIRO, a partir da decomposição em ambientes favoráveis $\left(\mathrm{P}_{\mathrm{if}}\right)$ e desfavoráveis $\left(\mathrm{P}_{\mathrm{id}}\right)$, para o índice $\mathrm{H}$ (Perfil do grão em mm).

\begin{tabular}{|c|c|c|c|c|c|}
\hline Cultivares e linhagens de feijoeiro & $\operatorname{Média~}(\mathrm{mm})-\hat{\beta}_{0 i}$ & Perfil do grão (índice H) & $\mathrm{P}_{\mathrm{i}}\left(10^{4}\right)$ & $\mathrm{P}_{\mathrm{if}}\left(10^{4}\right)$ & $\mathrm{P}_{\mathrm{id}}\left(10^{4}\right)$ \\
\hline IAC - Diplomata & $0,8111 \mathrm{a}$ & Cheia & 0,0007 & 0,0012 & 0 \\
\hline LP 01-38 & $0,7733 \mathrm{ab}$ & Semi-achatada & 0,0016 & 0,0008 & 0,0027 \\
\hline IAC - Alvorada & $0,7711 \mathrm{abc}$ & Semi-achatada & 0,0019 & 0,0022 & 0,0016 \\
\hline LP 02-130 & $0,75 \mathrm{bcd}$ & Semi-achatada & 0,0028 & 0,003 & 0,0026 \\
\hline Gen 96 A45-3-51-52-1 & $0,75 \mathrm{bcd}$ & Semi-achatada & 0,003 & 0,0031 & 0,0028 \\
\hline Gen 96A3 P1-1-1 & 0,7444 bcde & Semi-achatada & 0,0036 & 0,002 & 0,0055 \\
\hline CV- 48 & 0,7378 bcde & Semi-achatada & 0,004 & 0,0031 & 0,0052 \\
\hline FT- Nobre & 0,7356 bcde & Semi-achatada & 0,0042 & 0,0033 & 0,0053 \\
\hline IAC-Una & 0,7222 bcde & Semi-achatada & 0,0053 & 0,0044 & 0,0064 \\
\hline LP-98-122 & $0,7256 \mathrm{cdef}$ & Semi-achatada & 0,0053 & 0,0045 & 0,0063 \\
\hline $\mathrm{Z}-28$ & $0,7233 \mathrm{def}$ & Semi-achatada & 0,0057 & 0,0064 & 0,0049 \\
\hline BRS - Supremo & $0,7156 \mathrm{def}$ & Semi-achatada & 0,0059 & 0,0057 & 0,0061 \\
\hline BRS - Requinte & 0,7144 def & Semi-achatada & 0,0063 & 0,0051 & 0,0079 \\
\hline Pérola & $0,7122 \mathrm{def}$ & Semi-achatada & 0,0065 & 0,0056 & 00,0076 \\
\hline BRS- Grafite & $0,7056 \mathrm{def}$ & Semi-achatada & 0,0079 & 0,0069 & 0,0092 \\
\hline IPR Siriri & 0,7033 ef & Semi-achatada & 0,0079 & 0,0046 & 0,0119 \\
\hline Gen 96A98- 15-3-52-1 & 0,7033 ef & Semi-achatada & 0,0075 & 0,0072 & 0,0078 \\
\hline BRS- Pontal & 0,6989 ef & Achatada & 0,0083 & 0,0075 & 0,0093 \\
\hline IAC- Carioca Tybatã & $0,6889 \mathrm{f}$ & Achatada & 0,0094 & 0,0083 & 0,0107 \\
\hline Média & 0,73 & - & - & - & - \\
\hline Coeficiente de variação (\%) & 2,12 & - & - & - & - \\
\hline
\end{tabular}

*Médias não seguidas da mesma letra diferem entre si, com nível de 5\% de probabilidade, pelo teste de Tukey.

\section{REFERÊNCIAS}

CARBONELL, S.A.M. et al. IAC-Alvorada and IAC-Diplomata: new common bean cultivars. Crop Breeding and Applied Biotechnology, v.8, p.163-166, 2008. Disponível em: <http:/ /www.sbmp.org.br/cbab/siscbab/uploads/bd6b9df0-168c8e69.pdf>. Acesso em: 13 ago. 2010.

CARNEIRO, P.C.S. Novas metodologias de análise da adaptabilidade e estabilidade de comportamento. 1998. 155f. Tese (Doutorado em Genética e Melhoramento) Universidade Federal de Viçosa, MG.

CARNEIRO, P.T.; PARRÉ, J.P. Importância do setor varejista na comercialização de feijão no Paraná. Revista de Economia e Agronegócio, v.3, p.277-298, 2005. Disponível em: <http:/ /www.economia-aplicada.ufv.br/revista/pdf/2005/ 6_\%20Artigo_19-08.pdf>. Acesso em: 13 ago. 2010.

CHIORATO, A.F. et al. IAC - Jabola and IAC - Esperança: common bean cultivars for market niches. Crop Breeding and Applied Biotechnology, v.9, p. 199-201, 2009. Disponível em: <http://www.sbmp.org.br/cbab/siscbab/uploads/ c8129491-875c-7779.pdf >. Acesso em: 13 ago. 2010.

COLLICCHIO, E. et al. Associação entre o porte da planta do feijoeiro e o tamanho dos grãos. Pesquisa Agropecuária Brasileira, v.32, p. 297-304, 1997.
LIN, C.S.; BINNS, M.R. A superiority measure of cultivar performance for cultivar $\mathrm{x}$ location data. Canadian Journal of Plant Science, v.68, p.193-198, 1988. Disponível em: < ht t p://article.pubs.nrc-cnrc.gc.ca/RPAS/ rpv?hm=HInit\&calyLang=eng\&journal=cjps\&volume $=68 \& a f p f=c j p s 88-$ 018.pdf $>$. Acesso em: 13 ago. 2010.

MELO, L.C. et al. Interação com ambientes e estabilidade de genótipos de feijoeiro-comum na Região Centro-Sul do Brasil. Pesquisa Agropecuária Brasileira, v.42, p.715-723, 2007. Disponível em: $<$ http://www.scielo.br/scielo.php?script=sci_arttext\&pid=S0100204X2007000500015\&lng=pt\&nrm=iso\&tlng=pt >. Acesso em: 13 ago. 2010. doi: 10.1590/S0100-204X2007000500015.

PERINA, E.F. et al. Avaliação da estabilidade e adaptabilidade de genótipos de feijoeiro (Phaseolus vulgaris L.) baseada na análise multivariada da performance genotípica. Ciência e Agrotecnologia, v.34, p.398-406, 2010. Disponível em: <http:/ /www.scielo.br/scielo.php?script=sci_arttext\&pid=S1413$70542010000200018 \& \operatorname{lng}=\mathrm{pt} \& n r m=i s o \& t \operatorname{lng}=\mathrm{pt}>$. Acesso em: 13 ago. 2010. doi: 10.1590/S1413-70542010000200018.

PUERTA ROMERO, J. Variedades de judias cultivadas en España. Madrid: Ministério da Agricultura, 1961. 798p. (Monografias, 11). 